\title{
A dentist from the north removed a tooth in a southman's mouth. american civil war (|86|-|865)
}

Keywords: well muscled right arm, tooth brushing, chewing, six month period

\section{Introduction}

"In the North, the federal government did not supply the troops with dental surgeons. Neither did the government recognised a special status to dentists. Dr John Sayre Marshall (1846-1922), a veteran from the 2nd Troop of Volunteer Cavalry from the State of New York, declared in Koch's History of Dental Surgery (1909): "Within the ranks of the American army, the only provided dental services were to pierce the abscesses of the gums and to extract teeth. The latter was often carried out by an hospital assistant, whose sole qualification for this task was to have a well-muscled right arm." The extractions were often incomplete and residual roots persisted in the mouth. They often led to subsequent problems (Figure 1). The soldiers of the Union often consulted civilian dentists and paid with their own salary for the subsequent expenses. Thus, when General Sherman's regiment arrived in Savannah, these men besieged the dental practices of the town. A dentist said of them: "The cases of emergency alone would have required the help of a hundred dentists during a six-month period." Even though the armies of the Old continent recommended their soldiers to take care of their teeth and whereas hygienists approved this approach to avoid "fevers and diseases", tooth brushing was rarely done. The food was absolutely devoid of vegetables and fresh fruits. In 1861, within the army of the Union, food was responsible for numerous cases of scurvy with a subsequent loss of teeth. As physical examinations at the time of admission in the Northern army were increasingly rigourous, decayed teeth, the lack of a great number of teeth or the diseases affecting the areas adjacent to the teeth became possible causes of exemption. And yet, archives showed that a few men were exempted due to poor teeth. Only $2,4 \%$ of the men who were examined were exemped for that matter. The abbreviation $4 \mathrm{f}$ was used to mention the lack of teeth. This acronym then became the symbol of military exemption due to disability. Dr Youngs stated that: "During the mobilisation of 1863 , out of the 255,188 men who were examined during the draft, 5,230 were exempted for dental reasons." Robert Bartholow, the assistant surgeon who was in charge of the Mac Dougall General Hospital, wrote in his book "Manual for the enrollment and the exemption of soldiers" (1864): "Decayed teeth or the loss of incisors or canines were grounds for exemption, not only because they prevented the soldier from tearing the cartridges apart or from properly chewing his food but also because these were obvious signs of poor general health. Even without incisors or canines, a man who has to reload his musket always finds a way to do it, even without teeth; perhaps will he lack rhythm and accuracy at the most? However, his poor general health is of particular concern. The inconvenience caused by the inability to properly chew leads to more important problems. A man who only lost his incisors shall not be exempted unless his loss of teeth is due to decays or other rotting teeth." Judging by this statement, a man who had lost his lower and upper incisors could find a place in artillery. Commanders in the field would soon understand that a soldier in good health was much more efficient than a soldier with poor general health."
Volume 10 Issue 6 - 2018

\author{
Xavier Riaud \\ National Academy of Dental Surgery, France
}

Correspondence: Xavier Riaud, National Academy of Dental Surgery, France, Tel 02407664 88, Email xavier.riaud@wanadoo.fr

Received: August 28, 2018 | Published: November 19, 2018

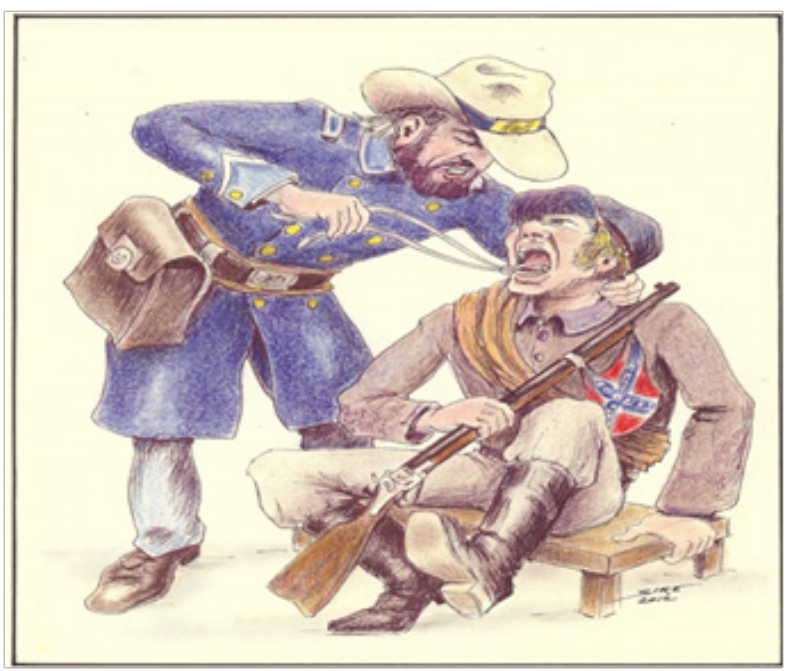

Figure I A dentist from the North removed a tooth in a Southman's mouth

\section{Acknowledgements}

None.

\section{Conflict of interest}

The author declares that there is no conflict of interest. 